\title{
Radio role-play - the use of a simulated radio studio in TEFL
}

\author{
Karel Zdarek
}

\begin{abstract}
This paper aims to present a particular role-play technique called radio role-play developed specifically for the use in ELT classrooms. The technique is defined within the context of drama education and language teaching, and characterized in terms of its unique features. Practical examples from teaching practice are provided. Any kind of teaching material (text/recording) can serve as an input for radio role-play. The content is contextualized within the fictional broadcast studio as the students take on roles of a host and their guest(s) - usually characters from the textbook articles, recordings, or any other teaching material. The setting of a radio studio is unique in terms of its close relation to a real studio setting - sitting down at a table, facing the partner, possible use of microphones, jingles, soundscapes, etc. At the same time the setting provides protection, a sense of anonymity and safety, which results in high engagement levels. In practice, the radio role-play is organized as pair or group work, and the tasks are performed simultaneously. The outcomes of preliminary qualitative research (probe) carried out with high-school students aged 17-18 at B2 level are presented.
\end{abstract}

\section{Origins and development}

This paper aims to present a technique that emerged and evolved from the author's teaching practice. At the beginning there was an inspiration and personal experience with improvised performances taking place in a fictional radio studio, the idea of which later naturally infiltrated in the author's English teaching practice. What first was an intuitive experimenting using the general concept was later transformed through reflective practice into a role-play technique presented in this writing.

For the purpose of this paper, role-play will be understood as a technique commonly used in language teaching to develop fluency and possibly spontaneity and expression of emotions (Holden 1981: 1; Maley and Duff 2009: 1-2). Larsen-Freeman (2000: 80; 134) illustrates an effective use of role-play by different EFL methods such as suggestopedia or communicative language teaching throughout the history of English language teaching. In the teaching 
practice today, role-play is mostly used as a technique to propel communication, bring enjoyable experience, and consequently increase motivation (Porter Ladousse 2000: 7). In this perspective, radio role-play can be seen as a subcategory of role-play in EFL bearing its unique characteristics, possibilities and limits.

\section{Radio role-play - a new technique?}

Radio role-play as a theatre performance or Internet entertainment format is not new. There are various websites dedicated to producing and recording radio shows in English, mainly fantasy or sci-fi genres, e.g. RPPR Actual Play (2012) or Roleplaying Public Radio (2012). Another example of radio role-play can be a theatre group called Radio Ivo staging live improvised radio plays for theatre audience; the purpose of such use of the format is solely to entertain and amuse. Radio drama has recently been used in museums as a learning medium, as Farthing (2009: 109) concludes:

Making audio drama can be an active memorializing process, providing the means to know, to remember and to creatively interpret, linking personal imagined experience with public memory by bringing the past of another vividly into one's own present.

The idea of using the format for language teaching is not new either. Single activities using the concept of an imaginary radio studio can be found in drama or communication practice handbooks for language teachers. Klippel (1994: 128-129), Maley/Duff (2009: 117) or Porter Ladousse (2000: 63) provide examples of a possible use of the radio role-play, although the term radio role-play is not used in their writing. The application of the format in Klippel and Maley takes on the form of a project work suggested for recording or performance. Ladousse presents a role-play activity using the concept of a phone-in program through which people seek answers to their problems. What does appear to be new in the approach presented in this paper is the endeavour of a systematic approach to the use of radio role-play as a universal teaching technique, used for developing foreign language learners' communicative competence. The characteristics of the technique and classification of the medium genres and functions will be provided; technique will be illustrated by examples of application from the author's teaching practice.

\section{Characteristics of radio role-play}

Radio role-play activities employ the task-based approach (Ellis 2003: 76-77) to work with texts, recordings and visual input; students perform the tasks in a role of host and guest in a fictional radio studio. Radio role-play activities realized by the author were mostly organized as pair work allowing students to stay at their desks when role-playing. The classroom arrangement very 
closely corresponds with a real radio studio set up - the host and his guest being seated at their desks turned toward each other, consulting their notes if needed. Radio broadcasting with its characteristic physical setting, genres, language register and style has a clearly defined and shared denotation, or at least a denotation common to all the students within the cultural context. The correspondence in the physical arrangement and the shared denotation seem to make the imaginative situation feel more real and, therefore, easier for students to identify with the role.

As radio role-play activities are performed in pairs or groups simultaneously, there is hardly any room for students to be concerned about the others listening or watching anybody; everybody is occupied with their own task. The focus of the students is often intensified by the task, especially when distributed on a role card disclosed to the role-play partner. It may be inferred that the noise generated by an activity in progress and the focus on the task seem to create an imaginative soundproof wall around the individual imaginative studios in the classroom. This, however, is only the author's assumption, which has not been confirmed by interviews with the students and leaves room for further research.

\section{The didactic use of the technique}

\subsection{Basic forms of the classroom use}

The use of radio role-play in a language classroom offers a variety of possibilities whose range is probably best illustrated by the continuum of drama approaches in L2 teaching (Kao and O'Neill 1998: 6). Radio role-play can very well be placed anywhere on the scale from controlled/closed communication (scripted role-play) to open communication (improvisation, strategic interaction or even process drama).

Recordings of role-playing activities can serve as an immediate feedback; students and teachers can also include the recordings in their portfolios to monitor the student's progress. The outcome of individual role-plays, improvisations and scenarios can be recorded, transcribed, modified, rehearsed and eventually performed. The performance can range from a simple skit/scene performance for the rest of the class, or in the case of a larger project, it can be performed for school, family and friends. The possibilities are numerous. However, this article elaborates on the classroom practice, with an emphasis on the process.

In the basic classroom practice the students work in pairs (or groups) where one of the students takes on the role of a program host and the other is a guest. The main task of the host is to devise their set of questions and strategy for interviewing, conduct the interview, keep the time and to be in control. The main task of the guest is to answer the questions in accordance with the role and the task. The teacher sets or modifies the task with regard to the main didactic aim of the activity (Harmer 1998: 87).

In the author's practice it has been observed that the nature of each student's 
or a pair's performance differ with respect to their communicative competence and their personality, mainly temperament. Naturally, the performance of the students within one class can range from basic fulfilment of the given task to an artistic play in character with emotions and humour. In practice, pairing less confident and less competent students with their more advanced peers (Vygotski 1978: 86) has proved beneficial in terms of an overall successful progress of the particular activity. Additionally, the technique contributes positively to the students' engagement and the student/teacher talking-time ratio (Lewis and Hill 1992: 20) in favour of students.

The most significant finding (based on the author's practice) is that any content of the written or recorded text from a language course book ${ }^{1}$ can serve as relevant and ample input for a radio role-play activity. In other words, any character from or beyond any course book text can become alive in the simulated radio studio. The basic application of the technique using a simple reporting task may be encouraging not only for less confident students but also for teachers with little or no experience in process drama. The task of the teacher is to describe the setting, give clear instructions for the activity and start the role-play.

The most common and simple use from the author's practice has proved to be a follow-up speaking activity for a reading or listening text with a task where the host asks about the event and its details and the guest provides information about the event. Radio role-play can also serve as an immediate, improvised or semi-improvised alternative to comprehension questions, which are a ubiquitous part of reading or listening activities in language course books. Instead of reading and answering the questions in pairs, the task can be carried out within a role-play in the radio studio. Observing the current model of exploiting reading and listening texts suggested by Scrivener (2009: 175) (in his principle of task-based feedback circle), radio role-play can be used in the final comprehension-check focusing on details, or as a follow-up activity aimed at fluency, a particular language function, or activation of newly learnt grammar and vocabulary, to name a few.

When creating a radio role-play the teacher can adopt a post-modern approach and go beyond the text; that is, use the text as a basic information input and elaborate further on what is explicitly stated or only implied. Such ventures offer endless possibilities. This way the teacher becomes both creator and designer of the situation in a way that suits the activity aims. This approach may include for example:

- introducing a new witness of the same account with a different or more detailed viewpoint of certain aspects;

- introducing a new guest sustaining a contradictory opinion;

- focusing and elaborating on a particular detail of a story from the text that was only mentioned or implied;

\footnotetext{
1 The technique is not limited to course books only. Various sources of language input can be used, i.e. internet resources, newspaper or magazine articles, songs, poems, etc.
} 
- interviewing the person years later.

The process of creating a radio role-play activity starts with the text and the aim that the teacher intends to achieve through a role-play based on the text. Once the aim is set the teacher defines other variables, i.e.: the suitable type of a broadcast format, number of roles, role tasks, cueing material, and sets timing. When designing the activity, the teacher takes into account other aspects or variables such as the students' age, needs, intelligence and a language level (Harmer 1998).

Table 1: Example of the use of different tasks for different aims

\begin{tabular}{|l|l|l|}
\hline Aim & Show Host's Task & The Guest's Task \\
\hline Text comprehension & $\begin{array}{l}\text { Conduct an interview and } \\
\text { find out the following facts } \\
\text { about your guest, about } \\
\text { the situation and the } \\
\text { problem. }\end{array}$ & $\begin{array}{l}\text { Answer the questions of } \\
\text { the host. }\end{array}$ \\
\hline $\begin{array}{l}\text { Giving an account of an } \\
\text { event }\end{array}$ & $\begin{array}{l}\text { Conduct an interview so } \\
\text { that the listeners are } \\
\text { informed in detail about an } \\
\text { event. }\end{array}$ & $\begin{array}{l}\text { Give a detailed account of } \\
\text { an event. }\end{array}$ \\
\hline $\begin{array}{l}\text { Presenting (an invention, } \\
\text { product, process, services, } \\
\text { etc.) [Note that Dorothy } \\
\text { Heathcote's (1976) Mantle } \\
\text { of the Expert technique } \\
\text { can be applied here]. }\end{array}$ & $\begin{array}{l}\text { Inquire about the latest } \\
\text { technological invention. }\end{array}$ & $\begin{array}{l}\text { Present the latest } \\
\text { technological invention. }\end{array}$ \\
\hline $\begin{array}{l}\text { Giving advice } \\
\text { theng }\end{array}$ & $\begin{array}{l}\text { Read the letters from the } \\
\text { listeners (take phone-calls) } \\
\text { and ask your guest } \\
\text { additional questions. }\end{array}$ & $\begin{array}{l}\text { Give advice to listener's } \\
\text { problems from the position } \\
\text { of the most acknowledged } \\
\text { expert in the field. }\end{array}$ \\
\hline $\begin{array}{l}\text { Handling an argument, } \\
\text { approprict, mediation (using } \\
\text { forms) }\end{array}$ & $\begin{array}{l}\text { The host of the show } \\
\text { moderates the discussion } \\
\text { between two conflicting } \\
\text { parties. }\end{array}$ & $\begin{array}{l}\text { For two or more guests - } \\
\text { One guest's task is to } \\
\text { negotiate the best result, } \\
\text { which will probably be in } \\
\text { contradiction with the other } \\
\text { guest's objective. }\end{array}$ \\
\hline
\end{tabular}

\subsection{Improvisation}

Role-playing activities (unless scripted) involve some degree of improvisation, which is considered one of the most difficult-to-learn aspects of acting and drama. Improvisation is also a skill essential for effective communication and problem solving, and as a skill it can be trained and developed. In the classroom practice it is advisable to gradually shift from controlled to open communication; that is, start with semi-improvised role-playing activities 
during which students are given enough background information, specific tasks and even suggestions for possible solution(s). Later, when students are comfortable with the particular level improvisation, the teacher can gradually move towards improvised role-playing by providing fewer input, hints, etc. Johnstone (1979) suggests a broad array of warm-up activities and games aimed at developing specific aspects of improvisation (e.g. partnership, focus, status, etc.) that can be used to make students comfortable in their attempts to improvise. Some students may consider improvisation as high-risk and face-threatening; therefore, it is crucial to establish a sense of trust and safety within the group for such activities. The context of a simulated radio studio itself may be helpful - pairs/groups work simultaneously, pairs/groups are veiled by the noise that the activity generates, there is no audience.

\subsection{Broadcast formats}

The radio as a medium offers various broadcast formats (programs, shows) that bear universal characteristic features known to all students. The fact that the formats are well known contributes to easier adoption of the roles (host guest). Inventing an original and suitable name for the show will make the idea about the show more specific and might positively contribute to the students' engagement in the role-play. It is at the teacher's liberty as to which program type is chosen as long as it respects the nature of the task and an anticipated formality level. For example, to provide an account of events with the aim of practicing formal language with advanced students, the teacher is more likely to adopt the BBC news type of a program rather than a phone-in to the local funky pop radio.

The following list shows examples of possible program types:

- documentary

- interview

- advice program (phone-ins asking for advice or the host reading letters and an expert giving advice

- classified (phone-ins)

- dating (phone-ins)

- commented sports match

- radio play

- cooking program

- life-style program

- DIY program 


\subsection{Language functions}

Radio role-play provides an opportunity to practice all language functions. The shift in the linguo-didactic paradigm has marked the change of focus from the language system to language function. EFL now emphasizes the communicative competence and clearly defines the output for each level A1-C2 in terms of what a student is able to do (Council of Europe, 2001: 26-29). Below is a sample list of language functions that can be easily performed and practiced by means of a radio role-play activity:

Informing, describing, comparing, contrasting, offering, rejecting, apologizing, thanking, instructing, presenting, agreeing, disagreeing, advising, proposing, negotiating, compromising, accusing, warning, etc.

\section{Radio role-play in practice}

The following example activity was performed within a regular 45-minute English lesson at Johannes Kepler High School in Prague at the end of June 2012. This particular class had been using the radio role-play technique regularly from September 2011 to June 2012. They were 11 students aged 17-18 at B1+/B2 level and they had three, 45-minute English lessons per week. The didactic objective for this group was aimed primarily at developing spoken communicative competence, improving fluency and activating passive language knowledge. The activity was video-recorded for a more accurate account and reference.

The activity is based on the text promoting the sale of the product called floating island. It is mainly a description of a luxurious floating island of nearly $1,000 \mathrm{~m}^{2}$ intended for the market at $\$ 5.6$ million (Mihaly 2012). The short text is accompanied with tables providing basic technical data on energy supply, water storage, sewage and equipment. The source website offers numerous graphic renderings of the floating island, but these pictures were withheld until the very end of the activity so that the students could employ their imagination. The reading part of the activity follows a top-down approach to reading, from general to the specific. Within Harmer's ESA model it would be considered an ESASA boomerang sequence (Harmer 1998: 28).

In the initial part of the lesson (20 minutes) the focus was on reading and vocabulary:

- lead-in: teacher puts the title Floating island on the board and the students are asked to predict and discuss what the article might be about (Engage).

- students read the text individually (Study)

- students answer in pairs general comprehensive questions (Activate)

- students study the vocabulary in the whole class: they are given the list of eighteen vocabulary items (Fig. 2) as they chronologically appear in 
the text. The pronunciation, meaning and use of the words are discussed (Study)

- students discuss in pairs what the floating island might look like and collaboratively make a drawing based on the information provided in the text (Activate).

Table 2: The list of vocabulary for the students to use in radio role-play activity

\begin{tabular}{|l|l|l|}
\hline float & manufacture & mainland \\
\hline anchored & aim to & rumoured price tag \\
\hline vague resemblance & obviously & unclear \\
\hline fancy platform & renderings & cater to \\
\hline brainchild & $\begin{array}{l}\text { intriguing } \\
\text { /in'tri [U+02D 0 ] gir/ }\end{array}$ & for now \\
\hline Austrian-based & an alternative to & $\begin{array}{l}\text { information available this } \\
\text { far }\end{array}$ \\
\hline
\end{tabular}

In the second part of the activity students perform a radio role-play (Activate). For illustration two variations using one text are shown:

Variation 1 (5 minutes) - Aim: Students will be able to actively use the new, challenging, or passive vocabulary in context and reproduce the information from the text.

The teacher introduces and starts an activity by instructing students:

You will be working in pairs now. One of you is the host of a radio program called "Hard life of the rich". The other person is Mr. Gabor Orsos, the inventor and manufacturer of the floating island. The host of the show introduces and interviews their guest. Gabor Orsos's task is to present and promote the product to the listeners and the potential customers. Another task for both the host and Mr. Orsos is to use as many words from the list as possible and tick the ones you used. You have 5 minutes for the interview.

The students' output was not strictly an improvised interview, as most of the content was cued by the text input and the task. Students reproduced the information and the more advanced ones got creative by adding extra information, creating contrasts and initiating mock conflicts while staying within the boundaries of the topic and the program-type.

Variation 2 (5 minutes) - Aim: Students are able to present and defend their opinion while challenging an opinion of their partner.

The following role-play was performed in groups of three. The role-cards (Fig. 3) were created with the intention to introduce a conflict between the 
Table 3: Role cards for a floating island role-play

\begin{tabular}{|c|}
\hline $\begin{array}{l}\text { Manufacturer: You were invited to the studio to inform the listeners about your } \\
\text { product. This is a great opportunity to address your potential customers. Talk about } \\
\text { the advantages and defend the possible objections. Be kind and polite at all costs. } \\
\text { address sb. - oslovit koho, objections - námitky }\end{array}$ \\
\hline $\begin{array}{l}\text { Environmentalist: You feel that this kind of a product is a threat to the environment. } \\
\text { Besides the waste it produces you are concerned about its manufacturing process. } \\
\text { Moreover, there is a moral issue - luxury like this only contributes to greater social } \\
\text { differences. The money could be spent on something more meaningful. Warn the } \\
\text { public and try to persuade the manufacturer to stop the production. contribute - } \\
\text { prispět, threat - hrozba }\end{array}$ \\
\hline $\begin{array}{l}\text { Host: The show should be firmly in your hands, under your control. Make the show } \\
\text { balanced. Feel free to introduce new (made-up) facts to play with the balance and } \\
\text { to help one or the other guest. You have } 5 \text { minutes for the show - keep the time. } \\
\text { firmly - pevně, made-up - vymyšlené }\end{array}$ \\
\hline
\end{tabular}

floating island manufacturer and an environmentalist. The host's task is to sensitively play with the balance of power helping one or the other guest.

The teacher hands over the role cards. When students are finished reading, they are given an extra two minutes to make notes and prepare their strategy for the interview. The teacher invites students to start and the hosts open the show greeting the listeners and introducing the guests. Students are notified when there is one minute left. When the time is up the teacher signals the end of the activity and brings the class together for feedback.

Further options - The activity route-map above provides a basic example of how to use simulated radio studio in a language classroom. Below are examples of several options for further work:

Once role-play is in progress and both characters know the other person's aim, the teacher can pause the activity and ask students to exchange the roles and resume from the last line produced.

Students who came up with interesting situations, problems and solutions can be invited to act out their role-play for the rest of the group. The group's common experience from observing their peers can provide valuable source material for a follow-up discussion.

Role-play can be followed by a writing assignment in which students will look at the problem from a different perspective: they will be asked to maintain an opinion contrary to their own, or contrary to the character they had been playing (e.g. write a letter as a listener who has been deeply touched by the program).

Each of the role-played scenes can be followed by whole class reflection during which students are invited to share their opinions and feelings out of roles. In process drama reflections are quintessential part of the educational 
process (O'Neill 1995); suggestions and information retrieved from reflections serve as input for possible replay of the scene. For each scene reply new challenges may be posed to characters, forcing them to make decisions about the situation and thus involving them deeper on a personal, emotional and moral level. It is important to acknowledge students' choices, include them in the role-play and thus let the students experience the consequences of the choices they made.

\section{Students' evaluation of radio role-play}

The technique was evaluated in the class where it was systematically used for 6 months. A qualitative probe was carried out to identify general categories on which the next qualitative research will focus. In April 2012 the group was asked general open questions: "When we worked in the fictional radio studio, what was it like for you? How did you perceive it? How would you evaluate it?" The students answered the questions anonymously in brief, writing answers ranging from 60 to 100 words. The following points occurred repetitively and expressed positive evaluation:

- Beneficial for learning the language;

- Increases fluency and confidence in speaking;

- Opportunity to activate vocabulary;

- Looking for inspiration in the peers;

- Helps to get rid of the timidity to speak;

- Reduced fear of making a mistake.

The students also emphasized points that can be seen as suggestions for improvement:

- Importance of balancing role-play with other areas of language learning (mainly grammar);

- The need for specific language material (textual input) and pre-teaching vocabulary; ${ }^{2}$

- One of students pointed out a drawback of radio role-play: Absence of the correct language model and less frequent error correction (this student preferred the whole class discussion).

\footnotetext{
${ }^{2}$ Sometimes the role-play activities were developed on the spot as a spur of the moment decision and in these often no text, cues or role-cards were used.
} 
The answers provided a valuable feedback and revealed several general topics (feeling of being in a radio studio, inspiration, emotions, shyness, suggestions for improvement), which were addressed in more detail in the interviews with seven students from the same class in May 2012. Six students were interviewed in pairs and one student was interviewed individually. The interview outcomes for individual areas of interest are presented below. Some points are illustrated by a quoted answer with the student's name changed to ensure anonymity of the research.

\subsection{Does it feel like being in a radio studio?}

The interview outcomes do not suggest that students have a strong feeling of being in the studio. Nevertheless, some say they feel more like being in a broadcast studio than in a classroom, and some say, "It's something in between".

\subsection{Seeking inspiration}

Students indicated their need for specific input (text, vocabulary list, tasks) to hold on to when acting in a role-play. Another aspect determining the level of inspiration and creativity is the choice of the topic; the more interesting a topic, the more associations and ideas it generates. As one of the students said: "The topic is a problem - it doesn't always fit and it determines how successful the situation turns out." (John, I28). On the other hand, some welcome the pressure of having to think on their feet: "I think it's good that a person must start from scratch and suddenly create some kind of a story." (Rick, I27). The success also "depends on how compatible the partners are" (Mary, I60).

\subsection{Expressing emotions}

The way emotions are expressed depends on the topic and the kind of emotions involved in the role-play. Some take it more seriously: "I can identify with someone's situation: for example, I can imagine I am in a refugee camp." (Peter, E14). For some it is even easier to express emotions when they are in the role (Rick, E45). If the topic is serious and in a real situation sadness or grief would be expressed, some students tend to turn it into fun or come up with absurd situations and solutions: "The emotions are pretended and taken as fun." (Lucy, E83). "We can say to each other things we wouldn't normally say and we know it is just humour." (Lucy, D86) Or, "We take it in a light-hearted way." (John, E38). There are also language use concerns which conflict with the expression of emotions: "Sometimes it consumes me and it's alright, but it's hard to start with emotions right away when I am uncertain about my language." (John, E32) 


\subsection{Feeling shy?}

Students in this group know each other well and have no reason to be shy in front of each other. However, some said that they are much more comfortable speaking in groups or pairs rather than in front of the whole class. There were repeated instances when students' answers referred to being afraid to make a language mistake or feeling ashamed when they realize they made one. "No, I don't feel shy; it's just uncertainty in the language. (John, S41) or "It depends on whom I work with in a pair, if it's someone who speaks English well, I make use of it, but then I am a little shy in front of him. I don't feel shy when I know that everybody is supposed to take on the role. The problem is English rather than the role-playing." (Mary, S65). For one of the students, role provides protection against fear and shyness: "It is better to be in the role: when I make a mistake then I make it as a character, not as Lucy. I am then less shy that I will make a mistake." (Lucy, S71).

\subsection{Suggestions for improvement}

In the interview students made valuable suggestions to improvement or stressed successful practice that they wish was used regularly. As mentioned, students prefer specific material, e.g. they specifically ask for list of words they are supposed to use during the role-play. (Peter, IM19). The choice of topic is crucial: "Choose such topics that would be interesting for most of us." (Rick, IM30)

It was also pointed out that the roles of the guest and moderator are not balanced; students feel the host role usually gets less talking time (Rick, IM23). When devising the role-play, the teacher should make sure that both roles have specific and equally valuable and challenging tasks. Generally, the host role should be given to students who are more extrovert and more communicative. Rick's suggestion applies to the cases when the host role is given to quiet, introverted students who can loose control of their program.

Not everyone is in favour of role-playing. One of the students in this group preferred whole-class discussions: "I prefer talking with the teacher because of the model of English and error correction. Peers usually don't correct their mistakes. They can even learn mistakes from one another." (Lila, IM51). This is a valid point and it is up to the teacher to ensure that this student is monitored or recorded and gets relevant feedback.

\subsection{Conclusion}

From the interviews, it can be concluded that the students in this particular group:

- generally perceive the radio role-play techniques as enjoyable and beneficial; 
- see the technique as an instrument to get them talk and help them become more fluent;

- do not seem to have a particularly strong "sense of a radio studio" or do not care much about it;

- find the choice of the topic crucial;

- welcome integrating the use of the specific vocabulary in the role-play task;

- perceive shyness not as being shy when acting but being worried about making a mistake in the target language and about loosing face in front of the teacher or their more advanced peers;

- tend to look for solutions and the words to express it in Czech and then translate them in English (some students only).

The interviews clarified the information gained in the initial probe and revealed a few new points of observation, such as the sense of being in a radio studio, shyness about incorrect English and translation from Czech to English. The students' feedback and evaluation was a valuable contribution for an upgrade and improvement of the technique and its use in EFL classes in the future.

\section{Teacher's evaluation}

The main aim set for the school year - to increase the fluency while maintaining an enjoyable working atmosphere, a sense of achievement and motivation - has been accomplished (based on both my and the students' observations). If some role-playing activities were less successful in terms of students' engagement and motivation, it was due to the choice of the topic. In the future more attention should be paid to the choice of suitable topics and tasks or even encourage students to contribute with their ideas for topics and situations.

There are two things in radio role-play that the teaching practice proved to be challenging: the organizational aspect of running the activities and creating a feeling of being in the radio studio. For the basic types of radio role-play activities (the host and the guest - a person from the article) it was sufficient to explain the context, explain the task for each of roles and have the students start the activity. However, some role-play activities were more complex involving three or more characters and/or more stages, while each stage was introduced with a new task for each character. This complexity is reflected in the organizational challenges. The main reason was the fact that different groups worked at a different pace; some were drawn into the activity and lost track of time. The instructor's reminder about time (e.g. there is one minute left) interrupted the flow of the activity. Sometimes the pace in each group was so different that while half of the class managed to carry out the task the other 
half was barely halfway, getting stuck in a futile argument over an insignificant point. Finally, distributing role cards for a 3-role activity of 2 or 3 stages (tasks) is quite demanding in terms of preparation and timing.

\section{Upgrade for future practice}

From the preliminary research it was concluded that the students in the interviewed group didn't have as strong "radio studio feel" as I had expected. In future research applications of the technique, new features will be applied to strengthen the feeling of being in the radio studio:

A "jingle" or a signature tune is a common radio station feature that immediately creates an atmosphere, feeling and a clear idea of what kind of program and style of hosting the listener may expect. Using such tunes might help provoke a more specific and realistic feeling of being in a radio studio, and also could be used to start off an activity simultaneously. The jingle could also be used to end a radio role-play activity. The concluding jingle could be gradually fading in signalling the nearing end of an activity. It would be beneficial to have several jingles for a different type of a program, e.g.: serious news, popular gossip news, psychology today, DIY program, etc. to induce a different mood and energy. The jingles could be recorded by students themselves or produced live using musical instruments or soundscapes.

To enhance the radio studio feel, a microphone could be placed on the table in front of the host and the guest(s). The activity could be recorded for feedback or for further editing and introducing as a product. If not equipped with suitable electronic devices or skills to use them, a teacher could collect old, used, non-functioning microphones to use them as a prop that might enhance the studio feel as well.

Students who decide to act out their role-plays for the rest of the group could use real microphones and the program would be broadcast from the speakers. To enhance the "studio feel" both for listeners and performers, performers might be separated from the audience by a screen, or the performers would just simply turn and face the audience with their back.

A rather significant upgrade would be to develop an application that combines the functionality and features of a classroom management software (such as LanSchool) and professional radio broadcasting software (e.g. MegaSeg). Such an application would run on tablets or laptop computers and it would enable the teacher to assign students to groups, assign tasks to individual groups or students, to work with them in the classroom at the same time, and in the virtual workspace on the screen in real time. The teacher could, in fact, define what content displays on whose screen, and when, and thus transfer messages, instructions, cues, or feedback. This way setting a task for role-play would become incomparably simple. The graphic user interface would display a timer, leaving the time management to the students' responsibility. The software could make use of the speakers, the integrated microphone, and the data transmission via VoIP, allowing for all the advanced features of a language 
audio lab. Similarly to the monitor displaying functions, the teacher would be able to determine who can hear whose microphone input. The teacher could unobtrusively listen to a chosen group or pair, taking notes of the language used, errors made for delayed error correction or feedback.

\section{Conclusion}

Radio role-play might serve as a universal technique for teachers with very little experience in drama education to promote lively communication, and develop students' fluency in a second language, using elements of drama. This technique is characterised by unique features and possibilities of radio as a medium, and offers various ways for making use of these possibilities in EFL classes. Student evaluations of the technique have shown some interesting findings in terms of perception of the radio role-play. In addition, the students came up with interesting suggestions for improvements that will be incorporated in the future practice and research.

To conclude, I believe there is a great potential and power in the medium of radio to be explored and as Farthing asserts, 'audio is undergoing a renaissance in education' (Farthing 2009: 107). The question is, will language teachers have the courage to cross over to the "as if" world, exploring and harnessing its potential?

Bibliography

Council of Europe (2001): Common European Framework of Reference for Languages: Learning, Teaching, Assessment. Cambridge: Cambridge University Press

Ellis, Rod (2003): Task-based Language Learning and Teaching. Oxford: Oxford University Press

Farthing, Anna (2009): Audio Drama and Museums: Informal Learning, Drama and Technology. In: Anderson, Michael; Carroll, John; Cameron, David (eds.): Drama Education with Digital Technology. London: Continuum, UK

Harmer, Jeremy (1998): How to Teach English. Harlow: Addison Wesley Longman

Heathcote, Dorothy (1994): Drama for learning: Dorothy Heathcote's mantle of the expert approach to education. Portsmouth, NH: Heinemann

Holden, Susan (1981): Drama in Language Teaching. New York: Longman

Johnstone, Keith (1989): Impro: Improvisation and the Theatre. London: Methuen Drama 
Kao, Shin-Mei, O’Neill, Cecily (1998): Words into Worlds. Stamford: Ablex Publishing Corporation

Klippel, Friederike (1994): Keep Talking. Cambridge: Cambridge UP, Print.

Larsen-Freeman, Diane (2000): Techniques and Principles in Language Teaching. Oxford: Oxford University Press

Lewis, Michael; Hill, Jimmie (1992): Practical Techniques for Language Teaching. London: Commercial Colour Press

Maley, Alan; Duff, Alan (2009): Drama Techniques in Language Learning: A Resource Book of Communication Activities for Language Teachers. Cambridge: Cambridge UP, Print

Mihaly, Csikos (2012): Orsos Island Shows (Retrieved June 6, 2012, from http://orsosisland.com)

Morris, Susan; Stanton, Alan (1996): The Nelson First Certificate Course. London: Longman

O’Neill, Cecily (1995): Drama Worlds. Portsmouth, NH: Heinemann

Porter Ladousse, Gilian (2000): Role-Play. Oxford: Oxford UP

RPPR Actual Play (May 29, 2012): Call of Cthulhu: Delta Green - Operation Eyes Down (Retrieved Dec 15, 2012 from http://actualplay. roleplayingpublicradio.com/about/)

Role Playing Public Radio (2012): Audio Comedy Shows (Retrieved December 15, 2012, from http://slangdesign.com/rppr/audio-comedyarchive/)

Scrivener, Jim (2009): Learning Teaching. Oxford: Macmillan Publishers Limited

Vygotsky, Lev Semenovich (1978): Mind and society: The development of higher psychological processes. Cambridge, MA: Harvard University Press 